\title{
Effect of sewage sludge on the marine environment: a case study in Liverpool Bay
}

\author{
R. BEST, G. AINSWORTH, P. C. WOOD \& J. E. JAMES
}

\section{Mr Best}

Although there was no obvious nuisance to abate in Liverpool Bay in 1969, Central Government initiated the study because the quantity of sludge to be discharged was increasing, the nature was becoming more complex, and the treatment more difficult and costly. Sea disposal which left no noxious end product and had generated no real complaint for 80 years was attractive, but the Government wanted to know the detailed process of breakdown and the controlling factors. The study programme had to be complete within itself so that a final report could be written in the short time available.

87. The discharge of sludge was only one of many polluting discharges to the bay: the rivers contained some of the worst fresh water pollution in the country and the coastal outfalls discharged much untreated sewage near the beaches. What criteria of pollution should be adopted to compare these various effects, what indicators should be chosen, and how should they be measured?

88. What use and user of the sea and beaches should be protected and what protection was economically and socially justifiable? What preliminary coarse studies were justifiable for the better design of the refined and more costly studies?

89. Although conclusions had to be cautious they indicated clearly that no nuisance arose from the present tipping and none was likely from the proposed future rate. As a safeguard a monitoring programme had already been started. Data collection alone was not enough; the data had to be evaluated and presented in a form suitable for field practitioners to design measures for optimized resource management.

Mr H. R. Oakley, J. D. and D. M. Watson

This comprehensive and carefully planned investigation was effectively led and managed by civil engineers, and the succinct account given in the Paper is evidence of the efficiency of this direction.

91. Perhaps the main criticism might be that the considerable cost was greater than necessary, and it would be of value if the Authors would indicate the cost of the work sub-divided into the principal sections, and say whether as a result of this experience they would tackle a similar task in the same manner or whether they would propose modifications to the approach, balance or techniques.

92. The two starting points of the investigation were the nature of the material to be dealt with and the possible effects which needed consideration. The brief reference to quantity and composition of the sludge in $\$ 11$ did not give as comprehensive a picture as that in reference 1 , which made it clear that there was a wide variety of sludge types and considerable uncertainty as to quantity. It could be expected that each sludge type would have significantly different characteristics and, insofar as $\S 30$ suggested that reliance was placed on the composition and behaviour of Manchester sludge, I wonder whether the Authors had information on other sludge types and what basis they used in making their projections of behaviour and effect.

Paper published: Proc. Instn Civ. Engrs, Part 2, 1973, 55, Mar., 43-66. 
93. As to the effects considered as set out in $\S 12$, there are three notable omissions. The first, which is not surprising, is the absence of reference to bacterial quality; the others, which I expected to see mentioned, are amenity and conservation considerations.

94. As to conservation, it is often alleged that dumping sludge to sea constitutes waste of organic and inorganic fertilizers, and it would be interesting to know the Authors' view. However, the amenity consideration is perhaps the more important. The use of the title Out of sight, out of mind $^{2}$ presumably should not be interpreted as meaning that if the dumping ground were sufficiently far off-shore, no consideration need be given to visual aspects. There is some evidence that floatable material in sludge is a potential nuisance in marine disposal and that the grease content is also important in relation to slick formation. With this in mind, do the Authors feel that there is any necessity to reduce, so far as practicable, the content of floatable material and of grease, and do they feel that digestion of sludge before discharge is desirable, both from this point of view and as a buffer against the accidental discharge of toxic sludge?

95. I was pleased to see a note of caution on the use of Woodhead drifters. Although this is a comparatively cheap and easy method of investigation, I have found that results are difficult to interpret and are such as to suggest that Woodhead drifters do not necessarily simulate the behaviour of settled sludge solids. What other studies do the Authors think should be used to support drifter results?

96. The information given on sludge particle size is interesting but my experience is that this is an arbitrary classification which depends to some degree on the method used. Would the Authors say what method was used and whether they could relate their particle analysis and settling velocity information to the known effects of flocculation after discharge into the sea?

97. I found the references to stratification difficult to follow. In $\$ \$ 41-43$ it is implied that there was stratification and yet $\S 44$, on the two-dimensional model, states that complete vertical mixing was assumed, and in $\S 52$ reference is made to a vertical diffusion coefficient. I think it probable that stratification resulting from the efflux from the Mersey Estuary would be more apparent on the ebb than on the flood tide.

98. Would the Authors give more information about the correlation mentioned in $\S 48$ between mud colour and degree of oxidation? In my experience, the results of analysis of samples of mud from polluted areas are difficult to interpret and it is not easy to distinguish sewage solids from natural muds which might themselves have an organic content and a bacterial count.

99. Paragraph 55 refers to the re-entrainment of sludge particles. Was the evidence from the data obtained in the survey correlated with that from the pre-war WPRL investigation ? ${ }^{B}$ It is commonsense to suppose that sludge particles will behave in a similar manner to fine mud and silt and will accumulate in areas where fine sediments are found in the natural condition, and this suggested that a sediment survey would be valuable.

100. It is misleading to suggest that there is little other experience; valuable information has been published on the behaviour and effect of sludge in a marine environment in the Thames Estuary, the Clyde, off New York and at Los Angeles, and no doubt the full report took full account of this information.

\section{Mr S. H. Dainty, Greater London Council}

Apart from the benefits that might accrue in the Liverpool Bay and its surrounding land areas, the Paper serves to indicate the concern of Government and of Britain as to the need to protect the seas of the world from pollution, and will, I hope, set an example to other countries to carry out similar investigations.

102. However, I am a little disappointed that the results of the study do not encourage me to think that the example we are going to set is of the best. The Liverpool Bay study follows other studies, and I am thinking in particular of the recent 
GLC work, which is similar in the quantity of sludge discharged; but on that occasion certain definite parameters were set. These were based on complete digestion of all the sludge before discharge and treatment of all trade waste in a sewage works before being discharged to sea. The Authors should make clear their own intentions.

103. I am concerned that the course of events which may be followed in Liverpool Bay could set a poor example to other countries in the world, possibly by some misinterpretation of the information given in the text of the Paper.

104. Whether one considers refuse, semi-liquids, sewage sludge or water, the recent trends on waste disposal have been very much in the direction of recycling of useful constituents. There is a growing demand to conserve all the materials that can possibly be recovered from waste products. There is a case for re-use of many constituents in all these fields, but recycling demands a high degree of control to remove pollutants, possibly at source or through intensive treatment of wastes at a disposal site. For either case a heavier cost will often be involved.

105. It becomes therefore largely a matter of economics, and here judgement is needed as to whether Britain should adopt these controls and re-use materials to the greatest extent, or should adopt a cheaper form of disposal by way of dumping at sea.

106. I suspect that there is no simple answer to the question and taken either way the economic effect may be minimal. Nevertheless, on the background of the European Economic Community one should hesitate to choose the necessarily cheapest form of disposal which might set in motion an unacceptable pattern of events.

107. The Paper offers little information on which to judge the overall perspective and it may be that the complete report covers such matters. If it does, the Authors should state as much; if it does not, then comments on parameters and degrees of monitoring are invited.

\section{Mr M. A. Puttock, Sir Frederick Snow \& Partners}

With the steady growth of population and industry Britain is facing a situation in which greater and greater quantities of sludge must be disposed of. There are numerous methods of land disposal, but the sea does offer a ready and economic solution to the problem for those communities within easy reach of the coast.

109. However, the Authors have clearly shown that one cannot assume that the sea can take unlimited quantities of waste without some form of verification that it has the capacity to absorb such tipping without causing harm to the marine environment. It is essential that the present state of the receiving waters is checked and a prediction made of the likely effect that any given discharges within a prescribed area might have. If this research shows such tipping to be acceptable, then and only then should permission be given for sea disposal to take place.

110. My firm was connected with a similar study carried out for the Greater London Council, which considered the disposal of sludge from the GLC sewerage area into the southern section of the North Sea. It is interesting to compare the techniques and the investigations carried out in each of the studies. In general the patterns in both were similar, but in the Liverpool Bay study greater attention was given to plant nutrients, marine organisms and fisheries, and this indicated that no adverse effect was likely to occur due to marine tipping.

111. Did the Authors investigate surface drift, and were drift cards released during the study? I have in mind that the prevailing winds are south-westerly and that the disposal of large quantities of sludge into shallow water could cause discoloration and a surface slick, which under certain conditions could travel shorewards. Also, if the sludge was not carefully screened before tipping, floatables could be put into the sea and carried ashore by wind action.

112. Another question I should like to put is on the direction of the sea bed drift as shown by the Woodhead drifters. A total of 1775 of these was released and $75 \%$ were recovered. Did these reach the shore and, if so, which shore, or were they retrieved at sea by vessels engaged on the study or by fishing boats? If the drift was 
shorewards, was it feasible for particulate solid components of the sludge to be washed up on the beaches before they had been rendered innocuous?

113. The information given in the Paper outlines a comprehensive approach to the investigations needed before marine disposal can be accepted. To some extent these echo the GLC study, and I would like to suggest that a pattern has been established which could well be adopted for similar investigations in the future. Has the Department of the Environment considered setting out a general directive for such future studies in which its agencies and other outside authorities might be involved?

\section{Mr R. W. Horner, Greater London Council}

The oxygen depletion given in Fig. 12, with the future dumping of $75 \%$ of sludge, seems rather high compared with the figures for the dumping of sludge in the Barrow Deep by the GLC. In 1972 about 140000 dry tons were dumped in the Barrow Deep and I cannot recall a depletion greater than about $4 \%$, the oxygen concentration being $96 \%$, being shown in any of the surveys carried out. In most cases the figures were much lower than this - of the order of $2-3 \%$ depletion. Why is this? It would seem that the vertical distribution and the high degree of mixing assumed in the model would give a slightly favourable answer. One would have thought that in fact there would not be such good mixing and therefore there might be greater depletions on the surface with the tendency of the sludge to rise to the surface.

115. I gather that it was envisaged that the sludge would be very mixed-surplus activated, humus, raw and digested sludges. I feel that it would be wise to digest all sludge before pumping it through a pipeline. On a number of occasions when raw sludge has been pumped through pipelines, there has been trouble with the pipeline greasing up. If the sludge was all digested, would the oxygen figures shown in Fig. 12 be better? I am conscious of the fact that digestion is the only real treatment process in sewage treatment, the other processes merely concentrating the pollutants.

116. With regard to Table 2 , why was only carbonaceous oxygen demand considered? What about the nitrogen content? My guess is that the oxidation of the nitrogen would take too long and that the carbonaceous figure would be that of the initial phase.

117. I was intrigued with the BOD sludge figure of $50000 \mathrm{mg} / \mathrm{l}$, having myself done a deduction based on the fall in BOD in primary sedimentation, when normally for every $1 \mathrm{mg} / \mathrm{l}$ of suspended solids removed there is approximately $1 \mathrm{mg} / \mathrm{l}$ of BOD reduction. I worked out that a $5 \%$ sludge should therefore have a $50000 \mathrm{mg} / 1$ BOD, and it was interesting that this was confirmed. Was this figure for a $5 \%$ sludge?

118. With regard to $20-25 \%$ of the fish landed at Conway being taken within 13 $\mathrm{km}$ of the sludge disposal area (mentioned in $\S 40$ ), will the publication of the report have an adverse effect on the sale of fish landed at Conway?

119. Is there any public prejudice in regard to fish caught adjacent to the sludge disposal area?

Professor A. R. Halliwell, Civil Engineering Department, Heriot-Watt University, Edinburgh

As a member of the Working Party the remarks by Mr Dainty cause me considerable concern. It was certainly not the intention of the Working Party to 'set a poor example to other countries of the world'. If anyone fears that this may be the result, it is presumably because he has seriously misinterpreted the Paper or the Paper does not give adequate expression to the views given in the report ${ }^{2}$ of the Working Party or the Working Party have not managed to express their views clearly in the report. It may indeed be the combined effect of all three possibilities mentioned. It is perhaps pertinent to note that this Paper, as no doubt the Authors will agree, is a résumé of the report, and that in a comparatively short paper like this many points have had to be considerably simplified while others have not been mentioned at all. Parts of the 
Paper express the views of the Authors only and were not considered by the Working Party. One example of this arises in the first sentence of $\$ 76$ : this sentence implies that the capacity of the sea to deal effectively with wastes is limited in some localities but is not limited in other areas. My own view would be that the capacity is limited everywhere and the capacity has been exceeded in some localities.

121. One cannot ensure that any report will not be misinterpreted but $\mathbf{I}$ hope that any study of the full report will show how carefully all the factors involved need to be considered before any proposal to dispose of sludge at sea can be sanctioned. In particular the various safeguards mentioned in the recommendations of the report should indicate how serious the Working Party consider the question of disposal of wastes at sea.

122. Consideration of recycling of the useful constituents of the waste products was outside the terms of reference of the Working Party $(\$ 10)$. I agree with Mr Dainty's general sentiments on this topic. Therefore, the conclusions of the Working Party do not mean, and should not be interpreted as implying, that dumping at sea is believed to be the best method of sludge disposal; indeed, conclusion 6.17 in the report hints at this when stating, 'Bearing in mind the need for economic sludge disposal we conclude that the sludge disposal ground is well sited."

123. The usefulness of drifter information has been questioned; indeed it is sometimes suggested that the results of a sea bed drifter study can be misleading. In this connexion it is perhaps unfortunate that the Authors state $(\$ 71)$ that 'some drifters released seaward of the present spoil ground reached the coast earlier than those released at the same time from points nearer the shore'. This statement, without further explanation of the particular results, may appear to give some substance for doubting the evidence obtained using drifters.

124. In appendix 7 of the report of the Working Party ${ }^{2}$ I was at some pains to consider this question of interpretation of the results of a drifter study. It must be readily admitted that if a drifter study is carried out without any other measurements being available then the results of the study may be difficult to interpret and that any explanation based on drifter results only may indeed be misleading. Particularly would this be the case if comparatively few drifters were released or if abnormal conditions prevailed while the drifters were at sea. However, in the area under consideration a considerable number of other measurements were available before the investigation took place. In addition, as described by the Authors, many other measurements were made by or on behalf of the Working Party. There is, therefore, sufficient background information for Liverpool Bay to ensure that any credible explanation of the drifter movement is not misleading.

125. The results of any drifter study are of course statistical; in general not all the drifters released will be returned, those released at one point will not all be picked up at the same point on the beach and they will not all take the same time to reach the shore, even when released together. This statistical nature of the results does not simply represent 'experimental scatter'. It reflects, in part at least, the statistical nature of the water movement (arising from turbulence) and in part the variations in the sea bed characteristics. It will not, therefore, be surprising if occasionally some drifters released seaward of the present spoil ground reach the coast earlier than those released at the same time from points nearer shore. Figure 7.36 of appendix 7 of the report ${ }^{2}$ shows that the behaviour of a sizeable group of drifters is perfectly consistent. The results in fact confirm theoretical predictions by Heaps ${ }^{7}$ that the residual velocity of the near-bed waters is greater at the spoil ground than nearer the coast. It follows that any movement of the spoil ground say 10-20 km seaward will not greatly increase the return time to the shore of the particulate matter of the sludge.

126. Results from sea bed drifters have to be interpreted. If they cannot be explained or if they appear to be in conflict with other information, it is not that the drifter information is wrong but rather that the explanation is not complete. The sludge will not travel in the same way and at the same speed as the drifters, but if the 
explanation of the movement of the sludge does not take into account the important factual information of the drifters then the explanation is lacking.

\section{Dr A. L. Downing. Water Pollution Research Laboratory}

On the point of dissolved oxygen depletion the question was raised as to whether nitrification was taken into account and I would say that it was. The confusion arises because in the table the total oxygen demand has been given as carbonaceous demand, but it is in fact a total oxygen demand, with an allowance for nitrification included within it. The detail of the calculation is on pp. 20 and 21 of the appendix to the main report. ${ }^{2}$

128. The subject of grease content throws up issues which are common not only to sludge dumping but also to the general problem of disposing of sewage to the sea.

129. The WPRL have been doing work recently to try to get some quantitative indication of the conditions which will give rise to the formation of slicks. It seems to be closely connected with grease content. For discharge of sewage from submerged pipelines it looks as though initial dilutions of more than about 80 will avoid the formation of slicks, but if the situation is one in which initial dilutions as high as that are impossible it is almost certain that a slick will be formed.

130. I am by no means certain whether people genuinely object to slicks or not. Some kind of social survey would probably have to be carried out to get some quantitative evidence on the matter. Of course, slicks are produced by natural phenomena as well as by the discharge of greasy material, and it may be that people take them as inevitable and are not necessarily put out by their presence. However, if the high initial dilution to which I refer cannot be achieved, some pre-treatment will be needed in order to prevent the formation of slick.

131. I should have thought it was unlikely that people would object to slick in the dumping area referred to which is about 15 miles offshore and not an area where water skiing or anything of that kind goes on. My impression from photographs is that there was not much evidence of slick outside the confines of the original dumping. A change from a mixture of primary and activated sludge to digested sludge would help, but I know of no quantitative evidence to assess the degree of benefit from this change. This kind of evidence is now being sought in relation to discharge of sewage. It is quite firmly said, by those who have studied the situation in areas where sewage is treated biologically before discharge, that biological treatment eliminates the problem of slick, and obviously this is something one wants to get sorted out in quantitative fashion, whether it really needs biological treatment or some process could be used which depends for its efficiency on the surface active properties of the material; for example, a process of fairly rapid flotation would take advantage of the surface active properties of grease and remove it by flotation, and possibly could be engineered reasonably cheaply. It is hoped that this is the kind of thing that will be looked at in the present phase of the WPRL coastal pollution research programme.

132. The most difficult part of this sort of exercise is to assess the effect on biological communities, and perhaps not just to assess the effect but to assess the significance of such changes as may be observed. The whole problem of biological monitoring is that the natural communities, even in the absence of a pollutional stress, are invariably subject to fluctuations. If the population is at all diverse there is a problem of determining its structure and the relative abundance of the constituent organisms. The Natural Environment Research Council recently appointed a Research Fellow to study the problem of biological monitoring, not in the sea but in rivers in the first instance. $\mathrm{He}$ is now at the WPRL and beginning to make some encouraging progress. However, in many cases in which biological monitoring has revealed evidence of pollutional stress the same conclusions might well have been reached purely from the chemical data, and one may have to face the possibility that, to avoid using excessive manpower, one may well have to rely very largely on chemical parameters accompanied by rather general examination of flora and fauna. 
Mr M. J. Barrett, Water Pollution Research Laboratory

I would confirm that on the comparatively few occasions I was at sea in the dumping area, when ships were discharging, I was agreeably surprised to note the absence of objectionable floating material, and in most cases slicks were not very evident.

\section{Mr G. F. G. Clough, Howard Humphreys \& Sons}

I wonder what the effect of dumping sludge in sea water is on the components of the sludge.

135. I see that the sea water is described as containing 34 parts per thousand of dissolved solids. Since the sludge in the first case presumably was suspended in fresh water, there must be some osmotic effect. Were the settling tests carried out done by taking the sludge and dropping it quickly into the sea water or was it shaken up with the sea water first? If so, what sort of time interval was allowed for this osmotic effect to take place? What is the effect of dumping living organisms in salt water? What sort of viability have they? What was the diameter of the column in which the settling tests were carried out? Was there any correlation obtained between the results of the settling tests shown in Fig. 11 and the field tests carried out subsequently?

\section{Mr Ainsworth}

There were few objective comments when $O$ ut of sight, out of mind $^{2}$ was published and the constructive and critical comments now made are welcome. Although the Paper expresses personal opinions of four members of the original Working Party, the main report was very much a team effort and tribute should be paid to the other members of the Working Party who carried out most of the investigations on which the Paper was based. Condensation of its several hundred pages into such small compass was difficult.

137. The effects of coliform and pathogenic bacteria in the sludge were initially considered. The great distance of the discharge point from the coast and the immediate high dilution of the sludge indicated that any possible concentrations of pathogens from this source as the sea water approached the coast would be insignificant compared with background levels from existing coastal discharges.

138. Samples of the sludge from all the potential major contributors were analysed and are reviewed in appendix 1 of the Working Party's report. ${ }^{2}$ Regular routine analyses of the sludge cargoes are performed and, as recommended by the Working Party, further regular monitoring of Liverpool Bay is also being carried out to ensure that any predictions made were not over-optimistic.

139. It is obviously desirable to minimize the content of floatable matter, including grease, and the Working Party made firm recommendations that screenings should be separated from the sewage and kept out. Persistent plastics and other conservative materials will not be destroyed merely by chopping them up and returning them to the sewage flow.

140. Digestion of the sludge would obviously reduce the total oxygen demand during its stabilization in the sea, but oxygen depletion has not been shown to be a limiting factor in this area. Dissolved oxygen concentrations have so far been better than predicted under the worst-case conditions shown in Fig. 12. Digestion is a useful adjunct but it can be a fickle process and is it really necessary for sludge deposited so far from the coast?

141. The pre-war WPRL investigations referred to by $\mathbf{M r}$ Oakley were considered, but their data related to areas further inshore than the spoil ground. The more recent investigations covered a much greater area.

142. The method of determining particle size distribution utilized wet sieving which broke down agglomerates, so that true particle size was measured.

143. No one will disagree with Mr Dainty's general principles for the recycling 


\section{DISCUSSION}

and re-use of materials where possible. Industry has to be sited somewhere and, despite effective trade effluent control systems, complete removal of potential pollutants is not feasible. In the highly industrialized catchment area for Liverpool Bay there has been some excellent co-operation from industry in reducing the impact of its wastes on the environment. When the Working Party's report ${ }^{2}$ was drafted, the zinc concentration in the sludge was $6100 \mathrm{mg} / \mathrm{kg}$ dry solids. The average for 1972 was $3500 \mathrm{mg} / \mathrm{kg}$ and for the first quarter of 1973 was $2766 \mathrm{mg} / \mathrm{kg}$. Mercury concentrations for the same periods were 34,25 and $16 \mathrm{mg} / \mathrm{kg}$ respectively, and the initial relatively high concentrations for organochlorines (including polychlorinated biphenols) was reduced to $15 \mathrm{mg} / \mathrm{kg}$ in 1972 and $5 \cdot 1 \mathrm{mg} / \mathrm{kg}$ during the first quarter of 1973 .

144. Mr Dainty implied that we might recommend sea disposal of sludge because it is cheap. One may be sure that the GLC and those serving Manchester and Salford initially adopted the method on mainly economic grounds although they were probably also influenced by the apparent absence of the residual problems frequently experienced with land-based disposal schemes. Sea disposal is not necessarily the cheapest method nor is it necessarily the best; it is just one intelligent use of the environment. Sludge cannot be made to disappear, it can only be converted into something else. It is my belief that, under proper control, sea disposal of sludge at suitable spoil grounds will have no more adverse effects than any of the alternative methods currently available, including incineration.

145. At the time the main report was drafted, the sludge taken to sea contained an average of about $8 \%$ dry solids. The BOD values are lower than those computed by Mr Horner, the five-day value being about $30 \%$ and the ultimate oxygen demand about $60 \%$ of the total solids concentrations.

146. No drift cards were released during the dispersal experiments, dye tracer being used to simulate the surface drift of the soluble constituents of the sludge and radioactive labelling, supplemented by sea bed drifters, to predict the destination of the solid components. Returned drifters had been recovered from the shore or within the estuaries. It is interesting that a line separating two near-bed systems seems to pass through the actual spoil ground. Drifters released to the west of this line tended subsequently to appear on the North Wales coast or Dee Estuary, whereas those released to the east tended to travel towards the Mersey Estuary. With strong westerly winds, the line appears to be diverted and most of the drifters tended to approach the Mersey system.

147. Mr Puttock asked if it was feasible for solid particles to reach beaches before being rendered innocuous. The sludge residues were only deposited in areas of existing mud so that sandy beaches and recreational areas remained clean. In any event, the data given in $\S 59$ and Table 2 would indicate that a high degree of oxidation takes place before they reach even the muddy areas.

148. The initial laboratory settling tests, allowing sludge to run from a tube terminating just below the surface of a static column of sea water, displayed the osmotic effect referred to by Mr Clough. The sludge formed a clump near the surface while salt water diffused into the interstitial water zones of the sludge which then disintegrated into separate smaller particles which settled. In the more detailed laboratory tests at the Hydraulics Research Station, a 'bottom-withdrawal' system based on Oden's method was used to measure settling velocities. The later sea investigations followed normal operational practice with the outlet ports at the base of the ship releasing sludge into the intensely agitated zone around the ship's screws promoting instant dispersion and dilution and thus aiding settlement.

\section{Dr J. E. Portmann,* Ministry of Agriculture, Fisheries and Food}

Mr Oakley, dealing with nutrients, questioned whether we were satisfied with our knowledge of the nutrient budget. I do not think it matters if it is only partially

* On behalf of Mr Wood. 
complete. It seems probable that there was an underestimate of discharges of nutrients from land but I believe we have stabilized the nutrient contribution from sludge disposal with some accuracy. What is important, however, is whether or not the nutrients are going to be beneficial. It is often assumed that the addition of nutrients to the sea is beneficial, but this is not often true. It is first necessary to establish whether or not nutrients of the area under consideration are limiting the production of fish or other types of marine life. Generally they do not, particularly in coastal regions and the Paper points out that there are adequate nutrients in the Liverpool Bay area. From this work there was some suggestion that there may be too many nutrients already. Phaeocystis blooms which are observed in the area are generally of adequate nutrients. It is then necessary to consider whether or not the added nutrients are likely to be harmful. This study strongly suggests that such is not the case, and that the amount derived from sewage sludge is very small compared with the quantities from other sources.

150. Professor Halliwell pointed out that the Working Party did not give unconditional approval for the dumping of all types of waste, including sewage sludge. The position of constraints on persistent substances such as mercury, cadmium and organochlorines has been mentioned. These substances are specifically banned from being dumped under the terms of the Oslo and London conventions, and the Ministry of Agriculture, Fisheries and Food seeks to restrict the quantities dumped at sea within the current voluntary scheme for control. These restrictions extend to sewage sludge, but traces of such materials are permitted in sewage sludge because it is recognized that it is very difficult to stop small quantities entering the sewers. We expect to see a trend over the years for the quantity that is allowed under the heading 'trace' to be reduced, and we are working very closely with the Department of the Environment and local authorities such as Manchester and Salford to advise them on this matter.

\section{Mr James}

Mr Dainty feared that we might have set an example which may not be of the best. We should like to feel that the example that has been set is in the use of techniques and in the care taken in data collection and the interpretation of results. We would not suggest that Liverpool Bay was a typical coastal area or that it was not necessary to study conditions elsewhere. I think we have made every effort to be conservative in coming to conclusions.

152. The Working Party has emphasized the need for monitoring and also for additional specific studies. The additional studies undertaken since the main report was compiled are of two types. There are the special one-off studies to fill gaps in our knowledge, most of which appeared following consideration of data from the initial fieldwork done in 1970 and 1971 . There are also the monitoring studies, and in this connexion we think in terms of a period of about 10 years.

153. One of the special studies was completed in 1972 by Dr Burrows and Dr Sharples at Liverpool University. Their earlier work had been carried out simultaneously with hydrographic studies and did not have the benefit of data now available. From the new work we have come to appreciate the effect of sea conditions at the time of sampling. The objects were threefold: to determine the effect of sludge on the sea water, to determine the time required to dilute the sludge and to determine the effect of zinc and copper concentrations in the sludge. The conclusions drawn from this additional study are that there is no indication of particular deterioration in water quality along the line of the residual drift from the disposal ground and that, with fairly typical conditions, i.e. not dead calm, dilution to non-inhibitory concentrations can take as little as two hours, as opposed to the 24 hours which we had previously deduced from calm conditions. This range of 2-24 hours may possibly relate to the range of rough and calm conditions. We have also come to the conclusion that it is the copper rather than the zinc which controls toxic action. 
154. Further hydrographic work off the Dee Estuary has been undertaken by Dr Bowen, to link up with data obtained in the Dee Estuary studies. Temperature and salinity have been recorded and derived densities and dissolved oxygen concentrations obtained at a number of stations over periods of 13 hours. Current velocity and direction were measured near the surface and at 3 metre depth intervals down to the bed. The conclusions which were drawn were that the density distribution is that imposed by the Mersey and the Dee, and that depletion of dissolved oxygen is not a problem. Saturation did not fall below 95\%. In relation to Mr Horner's point the $75 \%$ saturation shown in Fig. 12 came from an extrapolation of calculations of dissolved oxygen under present rates of sludge disposal backed up by actual measurements. There was some correlation and we considered that a pro rata depletion would represent the worst possible set of conditions; this gave a $75 \%$ saturation. The sixfold increase is a maximum ultimate figure. It is taking the worst possible case all round, and it is right that we should, but it is doubtful if it would ever be reached.

155. A further sea bed drifter study has been carried out by Professor Halliwell, and we hope to set in motion shortly an examination of the effect of coastal discharges, if only to eliminate one of the unknowns.

156. The monitoring studies are long term, to check possible changes. Regular sampling of sea water and continuous fluorimeter recordings to monitor the phytoplankton are proposed. The thin surface layers of the sea bed are being examined and the first cruise to obtain core has been undertaken. This, we envisage, might be done twice yearly, with cores taken from 26 stations; because of uncertainty of the effect on the surface layer of the bed of the coring operations, underwater television and videotape equipment are being used at least for the first exercise. In marine work one is never sure just how representative the samples are. The surface layer samples are to be examined for particle size, organic carbon, copper, zinc and polychlorinated biphenols, and with twice yearly monitoring we would hope to detect any changes early on.

157. We are hopeful that we may be able to map the mud areas both in-shore and in the intertidal areas. This is a difficult exercise, if only because the in-shore areas are difficult to get at, but we are hoping that there may be some development of equipment which will help in this. With regard to the intertidal areas, we hope that aerial surveys may help although Liverpool Bay appears to hold the record for the lowest and most persistent cloud base in the country. We may consider using multispectral filming and possibly thermal imaging with further developments.

158. A study has recently been undertaken by Mr Roos of the University College of North Wales on the in-shore fauna and an initial survey of the fauna at the spoil ground has been made. The latter could become a regular exercise.

159. Thus the Working Party did not just sit back after their initial studies published in Out of sight, out of mind. ${ }^{2}$ They have been active in starting on the work which they recommended without losing any time.

160. We would all agree with many of the remarks macis about the importance of eliminating persistent substances at or before they reach the sewage works. However, the Working Party's terms of reference precluded their investigation of this aspect. The Working Party was set up specifically to examine the effect of dumping sewage sludge in the marine environment of Liverpool Bay. It was not set up to look at the question of alternative disposal on land.

\section{Mr Best}

Mr Oakley asked for the estimated cost of the study. It had to be a computed cost, and we think it is somewhere in the order of $£ 250000$ for our study.

162. He also asked whether the Department of the Environment had any arrangements for organizing the format for future studies based on experience from past studies. They have not but this is something they very much want to get down to when they get the staff and resources to do it. In appendix 20 of the Working Party's 
report ${ }^{2}$ some views are given based on experience on the Liverpool Bay study only. This can be extended to take account of other studies; we want to do it.

163. An increased rate of sludge dumping in the bay will result from better estimates in the catchment area, and as a result of these better estimates we hope that the pollution load in the bay, from dumped sludge or from rivers, will be reduced so that when people get concerned about six times more sludge going in, they forget that a lot will be removed from the rivers in consequence.

\section{References}

6. Department of Scientific and Industrial Research. Estuary of the River Mersey. The effect of the discharge of crude sewage into the estuary of the River Mersey on the amount and hardness of the deposit in the estuary. Water Pollution Research Technical Paper 7. HMSO, London, 1938.

7. HeAPS N. S. Estimation of density currents in the Liverpool Bay area of the Irish Sea. Geophys. J. R. Astr. Soc., 1972, 30, 415-432. 